\title{
Effect of Clinical Aspects on Post-Endodontic Pain after Single-Visit RCT
} \author{
Denise Sanchez Gonzalez ${ }^{3}$, Nazario Gabriel Yañez Hernandez ${ }^{3}$ and Jorge Paredes Vieyra ${ }^{4 *}$ \\ ${ }^{1}$ Department of Histopathology, Autonomous University of Baja California, Tijuana Campus, Mexico \\ ${ }^{2}$ Department of Oral Surgery, Autonomous University of Baja California, Tijuana Campus, Mexico \\ ${ }^{3}$ Department of Oral Rehabilitation, Autonomous University of Baja California, Tijuana Campus, Mexico \\ ${ }^{4}$ Professor of Endodontics, Zona Centro, Tijuana Baja California, México
}

Fabian Ocampo Acosta ${ }^{1}$, Francisco Javier Jiménez Enriquez ${ }^{2}$, Mario Ignacio Manriquez Quintana ${ }^{3}$, Amairani

Submission: August 16, 2019; Published: August 23, 2019

*Corresponding author: Jorge Paredes Vieyra, Professor of Endodontics, Zona Centro, Tijuana Baja California, México

Abstract

Objective: The purpose of this research is to evaluate the association of clinical issues such as sex, age, tooth group, preoperative pulpal diagnosis, preoperative pain, instrumentation, and irrigation type with post-endodontic pain.

Materials and Methods: One hundred and forty of 147 patients (76 women and 64 men) aged 18-65 years were incorporated in this research. Thirty-five of 140 teeth were selected to the four enlargement techniques. The study strategy included four experts; each expert prepared 35 teeth. Control group, TFA, WON and PTN groups received final flushing with 6oC 17\% liquid EDTA gently administered to the WL through a cold $(6 \mathrm{oC})$ sterile metallic micro cannula attached to the Endovac system (Kerr Endo) for one minute. The root canals were then desiccated with sterile paper cones size \#35 and filled at the same appointment. Gutta-percha cones

Results: No statistically significant difference $(p>.05)$ between the groups were founded regarding level or period of pain. The postendodontic pain marks were analyzed 24 hours later in the four groups with a significant regression consequently. No statistically significant difference was seen between the 4 groups evaluated in the research in terms of analgesic consumption ( $p>.05)$. In general, analgesic consumption was limited to the next 24 hours after RCT in all the groups evaluated. Nobody of the 140 patients stated acute pain or flare-ups during the phase of the research.

Conclusion: The result of this research suggests that the use of aids like intra-canal cryotherapy technique with negative pressure irrigation reduces post-endodontic pain. Clinical factors such as sex, age, tooth group, and the instrumentation technique dos does not affect the results. Previous factors as preoperative pain, and irrigation type, can affect the occurrence of pain.

Keywords: Flare Ups; Pain; Post-Endodontic Pain; Postoperative Pain

Abbreviations: RCT: Root Canal Treatment; WL: Working Length; AF: Apical Foramen; AP: Apical Patency; AC: Apical Constriction; VAS: Visual Analog Scale

\section{Introduction}

Post-endodontic pain is a personal and subjective experience after root canal treatment (RCT) it is difficult to quantify and standardize. Pain management is indispensable in clinical procedures [1]. Endodontic pain contains a wide-ranging field which requests to be considered appropriately before arriving at a diagnosis. The patients widely fear pain of endodontic origin, accurate information of pain occurrence and strictness related with pulpal or periarticular illness and its decrease by RCT can change the attitudes of the patients, general dentists, endodontists, and other health care professionals [2]. Pain in
Endodontics includes a period time; previous, throughout, and subsequently RCT. Analyzing these limits also would help to choose the correct decision for treatment. During cleaning and shaping the canal, remains and irrigating solutions can be sent beyond the apex through RCT, and can lead to post-operative complications, such as intense pain or flare-ups. Therefore, adequate care of the working length (WL) can diminish the expulsion of remains through the apical foramen (AF) [3]. Numerous reports have presented that endodontic pain between two appointments can be due to preoperative pain, periapical lesions, fractured roots, retreatment cases. Pain after RCT can 
also result from the exacerbation of chronic lesion [1,2] of a nonvital tooth, [3] previously treated teeth or related with a type of flare-up. Accumulation of material remnant in the final portion of the root is a typical occurrence that causes obliteration of the canal.

This situation can be prevented if patency of the AF is maintained [4]. Presently, maintaining apical patency (AP) is suggested thru RCT [5]. Apical patency is the action of using a tiny hand file to maintain the AF open. It is a method that keeps the apex free of remains [6]. A patency instrument is described as a tiny bendable K-file, which is used through the apical constriction (AC) $[7,8]$. The instruments employed to gain AP are often the same instruments primarily used to negotiate the canal [9]. To improve clean and shape the canal, has been proposed technique like the concept of balanced forces [10]. The benefits of Balanced forces are that it reduces the chance of a change of WL, decrease canal alterations and formation of apical ledges, [5] permits maintenance of the integrity of the AC, [11] and increase the palpable appreciation of the professional through RCT [8]. Great advances in mechanical procedures and metallic properties have led to the improve of plentiful methods with innovative designs in current years. However, all methods and tools existing to this time are related to some level of the expulsion of remains $[12,13]$. The model of one-file for canal shaping was presented in endodontics [14] with the promotion of Reciprocal (VDW, Munich, Germany) and Wave One $\mathrm{T}^{\mathrm{TM}}$ (Dentsply Tulsa, Johnson City, TN) techniques. These metallic tools are made-up with a Ni-Ti alloy named M-Wire utilizing a novel thermal management procedure [15].

The watch-winding motion comprises an initial turning of the device in an anticlockwise way, during which the file enters and cuts the dentin, after that a sequence in a clockwise way, meanwhile the file is liberated. Most of the systems generate extrusion to some level; however, the volume of extrusion may vary $[16,17]$. Some other factors may disturb the occurrence of post-endodontic pain when AP was conserved in concordance to when it was not [18]. One of the unproven details for not operating AP is the probable passage of remains throughout the $\mathrm{AF}$, a clinical situation associated with post-endodontic pain [12]. Some other studies indicated that conserving AP would not generate postoperative complications, requiring it is reasonably made with other clinical aids [19]. The purpose of this research is to evaluate the association of clinical issues such as sex, age, tooth group, preoperative pulpal diagnosis, preoperative pain, instrumentation, and irrigation type with post-endodontic pain.

\section{Materials and Methods}

This study was completed at the Universidad Autónoma de Baja California, Facultad de Odontología, Tijuana, México. The review board accepted the study and was managed in agreement with ethical codes (including the World Medical Association Declaration of Helsinki). Four certified endodontists qualified in the processes, aids, and methods investigated took part in this project. The endodontists selected tracked a preestablished method for the Balanced Force technique, TFA, Wave $\mathrm{One}^{\mathrm{TM}}$, and Protaper Next instrument systems. The inclusion limitations were nonappearance of radiographic proof of apical inflammation and identification of irreversible pulpitis recognized by the positive reaction to thermal tests.

The principal author completed thermal pulp test, and four endodontists recognized radiographic procedures. Clinical necessities were established as follow:

i. The needs of the investigation were spontaneously accepted.

ii. Patients must be in physical and emotional wellbeing.

iii. Only vital teeth were selected.

iv. Positive thermal stimulation with EndoIce (Hygenic Corp, Akron, $\mathrm{OH}$ ).

v. Enough coronal structure.

vi. No endodontic treated teeth.

vii. Any drug used seven days' previous the study.

Exclusion parameters were: Endodontic treated teeth, pregnancy, No patient's consent, patients younger than 18 years. Necrotic teeth and teeth with periapical injury, root resorption, undeveloped apex, or a root canal with severe curvature $(>380)$ rejected also. The subsequent records were collected in clinical archives. Accumulating dental record and doing digital radiography, periodontal assessment, percussion, and cold test established the judgment of vital tissue. The diagnostic results were evaluated by relating the tooth's reaction versus an adjacent tooth with the same vital condition. The occurrence or nonexistence of pre-operative pain (yes/no) was noticed. Teeth (posterior/anterior) and location (superior/inferior) were also added.

\section{Patient Selection}

One hundred and forty of 147 patients (76 women and 64 men) aged 18-65 years were incorporated in this research (Figure 1). Sample size estimation was accomplished, rendering with a system for this particular objective (Cochran's method, 1986). Therefore, the 35 teeth distributed to each group were acceptable to approve an elemental sample. All patients contributed with maxillary or mandibular posterior or front teeth chosen for a standard RCT for prosthetic reasons identified with vital pulps. Patients rejecting to join the research, those with issues with single-visit RCT, those consuming a specific kind of medicine such as painkillers or NSAIDs, and participants with some unrestrained systemic ailment were excluded too. All applicants were knowledgeable of the aims and plan of the research, and printed permissions and patient consent form for this study was obtained before their addition. 


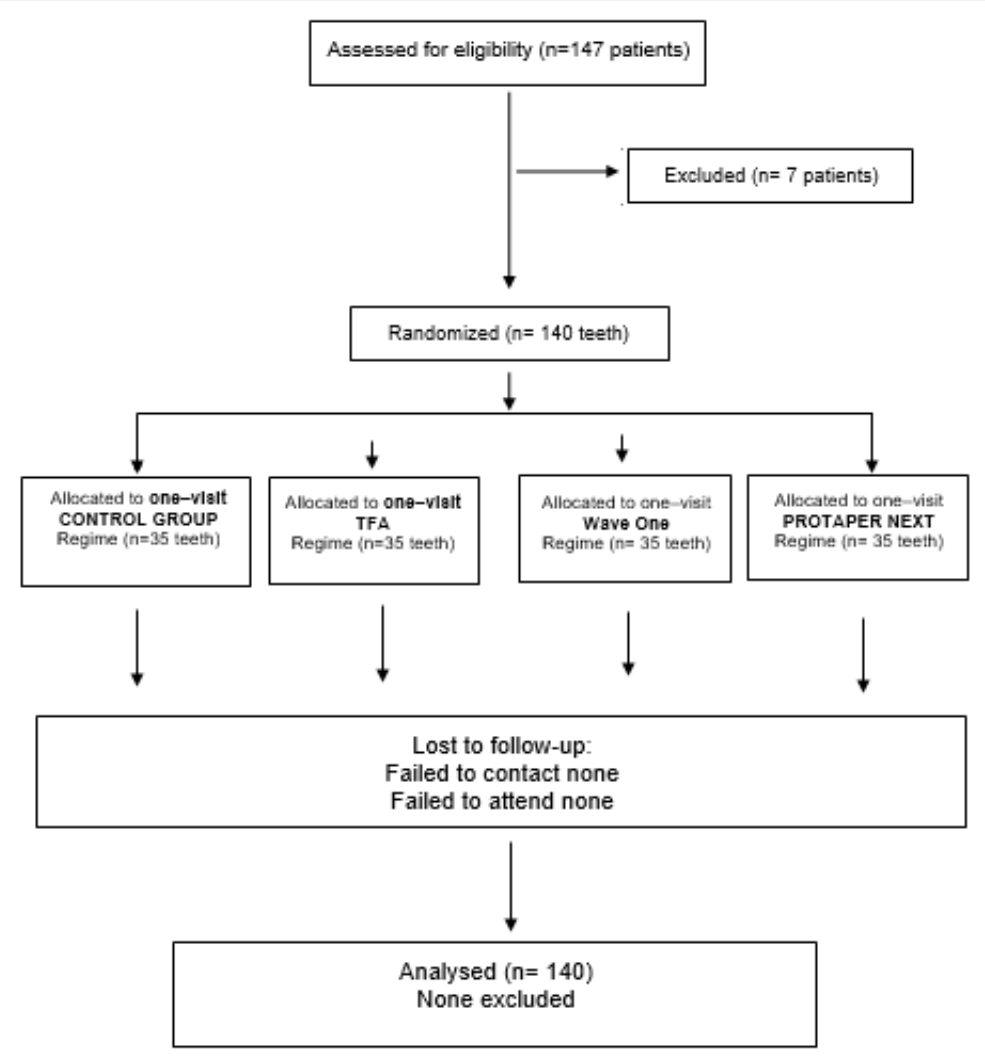

Figure 1: Flow diagram of the progress of phases of the study.

Table 1: Distribution by group of teeth.

\begin{tabular}{|c|c|c|c|c|c|}
\hline Clinical features & $\begin{array}{c}\text { Control Group } \\
\text { (CG) } \\
\mathbf{n = 3 5}\end{array}$ & $\begin{array}{c}\text { Twisted FA } \\
\text { (TFA) } \\
\mathbf{n = 3 5}\end{array}$ & $\begin{array}{c}\text { Wave One } \\
\text { (WON) } \\
\mathbf{n}=35\end{array}$ & $\begin{array}{c}\text { Protaper Next (PTN) } \\
\mathbf{n = 3 5}\end{array}$ \\
\hline Female & $19(54.28)$ & $19(54.28)$ & $19(54.28)$ & $19(54.28)$ & $76(54.28)$ \\
\hline Male & $16(45.71)$ & $16(45.71)$ & $16(45.71)$ & $64(45.71)$ & \\
\hline Maxillary teeth & $21(15.17)$ & $21(15.17)$ & $21(15.17)$ & $21(15.17)$ & $84(60.71)$ \\
\hline Incisors and canines & $1(2.85)$ & $2(5.71)$ & $1(2.85)$ & $1(2.85)$ & $5(3.57)$ \\
\hline Bicuspids & $4(11.42)$ & $4(11.42)$ & $3(8.57)$ & $4(11.42)$ & $15(10.71)$ \\
\hline Molars & $16(45.71)$ & $15(42.85)$ & $17(48.75)$ & $16(45.71)$ & $64(45.71)$ \\
\hline Mandibular teeth & $14(40)$ & $14(40)$ & $14(40)$ & $14(40)$ & $56(40)$ \\
\hline Incisor and canines & $1(2.85)$ & 0 & $1(2.85)$ & $1(2.85)$ & $3(2.14)$ \\
\hline Bicuspid & $3(8.57)$ & $3(8.57)$ & $1(2.85)$ & $2(5.71)$ & $9(6.42)$ \\
\hline Molars & $10(28.57)$ & $11(31.42)$ & $12(34.28)$ & $11(31.42)$ & $44(31.42)$ \\
\hline
\end{tabular}

$p=0.05$

Table 2: Distribution by group of teeth.

\begin{tabular}{|c|c|c|c|}
\hline \multirow{3}{*}{ Gender } & Female n (\%) & 76 & $(54.28)$ \\
\cline { 2 - 4 } & Male n (\%) & 64 & $(45.71)$ \\
\hline \multirow{4}{*}{ Type of teeth } & Mandibular molars n (\%) & 44 & $(31.42)$ \\
\cline { 2 - 4 } & Mandibular premolars n (\%) & 9 & $(6.42)$ \\
\cline { 2 - 4 } & Mandibular anterior n (\%) & 3 & $(2.14)$ \\
\cline { 2 - 4 } & Maxillary molars n (\%) & 64 & $(45.71)$ \\
\hline
\end{tabular}


Global Journal of Otolaryngology

\begin{tabular}{|c|c|c|c|}
\hline \multirow{2}{*}{} & Maxillary premolars n (\%) & 15 & $(10.71)$ \\
\cline { 2 - 4 } & Maxillary anterior n (\%) & 5 & $(3.57)$ \\
\hline \multirow{2}{*}{ Pre-operative pain } & Asymptomatic n (\%) & 73 & $(52.14)$ \\
\hline \multirow{2}{*}{ Diagnosis } & Symptomatic n (\%) & 67 & $(47.85)$ \\
\cline { 2 - 4 } & Acute pulpitis & 67 & $(47.85)$ \\
\cline { 2 - 4 } & Chronic pulpitis n (\%) & 73 & $(52.14)$ \\
\hline
\end{tabular}

\section{Random Selection}

Thirty-five of 140 teeth were selected to the four enlargement techniques. The study strategy included four experts; each expert prepared 35 teeth (Tables 1 \& 2).

\section{Treatment Procedure}

For each procedure, two carpules of Mepivacaine Hydrochloride 2\% with Levonordefrin 1:20,000 (Septodont, Cambridge, Ontario, Canada) was administered. In circumstances in which additional anesthesia was required, intraligamental Mepivacaine $2 \%$ was administered. After absolute isolation, the tooth was sanitized with $5.25 \% \mathrm{NaOCl}$. Cavity access was performed by using \# 331 bur (Dentsply International, York, PA), with high-speed and water cooling during the procedure. $5.25 \% \mathrm{NaOCl}$ was used to clean the coronal cavity. The canals were evaluated with \#10 K-type hand files (Flex-R ${ }^{\circledR}$ files, Moyco/Union Broach, York PA, USA). The standard procedures involved the following steps: Access was gotten; Smear Clear TM (Kerr Endodontics, Orange, CA) lubricant was administered at the entry of the canals. WL was first obtained with a \#10 k-file and the Root ZX locator (J Morita, Irvine CA, USA), following by subtracting $0.5 \mathrm{~mm}$ from the measurement, which was estimated with the assistance of a metallic ruler. With digital radiographic confirmation (Schick Technologies, NY, USA). A glide path to the WL was then established.

Pulpal cavity was dried with a sterilized cotton pellet. Lubricant was positioned at the entry of canals (i.e., measurements were made along humid canals). A \#15 file attached to Root ZX apex locator was used to calculate WL. WL was calculated with \#20 and \#25 files, respectively. If there was no arrangement among measures gotten by using the three files, the dissimilar data was reevaluated. If discrepancy continued, the measure conveyed with the thicker file was designated. WL was confirmed with a digital radiograph. In the event of dissimilarity between radiographic and electronic quantities, the last was designated. For the control group (CG), Balanced Force technique was employed. Canals were prepared and enlarged with hand Flex-R ${ }^{\circledR}$ files (Moyco/Union Broach, York PA, USA). The canals were enlarged using a \#40 instrument for tinny or curved canals and a \#55 file for wide canals. Gates-Glidden burs (Dentsply Maillefer) sizes \#1 - \#3 were employed at the twothirds of the root.

For mechanical enlargement, the rotary files were employed with a micro motor (Elements Motor, Sybron Endo, Glendora
CA.USA). Spin and revolution were established individually for each rotary file system employed. Twisted file adaptive, Wave One ${ }^{\mathrm{TM}}$ and Protaper Next instruments were employed in continuous brushing rotary motion and reciprocating mode correspondingly. Dentinal remains were removed from the instrument using a gauze, continuously to the next instrument change or after 3-4 in-and-out (pecking) movements allowing to the manufacturer's commendations. Each canal was flushed with $2.5 \mathrm{~mL} 2.5 \% \mathrm{NaOCl}$. Irrigation was accomplished using a $27-\mathrm{G}$ needle (Max-I-Probe; Tulsa Dental, York, PA) through access and a 31-G Navi Tip needle (Ultra dent Products Inc, South Jordan, UT) when getting the WL after each Ni-Ti file insertion.

a) Group TFA: SM1 (size 20,.04 taper) and SM2 (size 25, .06 taper) files were used consecutively with a single meticulous motion agreeing to the manufacturer's instructions.

b) Group WON: For the Wave One ${ }^{\mathrm{TM}}$ group, a file (25.08) was used to prepare narrow, straight, and curved canals, and a file (40.08) was used for large and wide canals.

Three in-and-out motions were used with lengths not beyond $3 \mathrm{~mm}$ in the three segments of the canal until reaching the estimated WL.

c) Group PTN: For the Pro Taper Next group, Sx files, X1, and X2 (Pro Taper Universal system; Dentsply, Ballaigues, Switzerland) were used for preflare and preparation of thin and curved canals and X3 and X4 (40/.06) for preparation of wide canals up to the WL. The instruments were operated using a continuous rotary brushing motion at a speed of 300 rpm.

Hand and rotary files were employed in just one tooth (single use) and then excluded. AP was conserved through all the procedures used by using a \#10 K-type file at WL. After the instrumentation phase, the pulp chamber was rinsed with $1 \mathrm{~mL}$ $2.6 \% \mathrm{NaOCl}$, agitated ultrasonically. Ultrasonic activation was done using an Irrisafe ultrasonic 20.00 tip (Satelec, Merignac, France) at $50 \%$ power of the Mini Endo ultrasonic unit (Kerr Endo) to place the tip $3 \mathrm{~mm}$ from the WL for 30 seconds per canal. Then, TFA, WON and PTN groups received final flushing with $60 \mathrm{C}$ $17 \%$ liquid EDTA gently administered to the WL through a cold (6oC) sterile metallic micro cannula attached to the Endovac system (Kerr Endo) for one minute to eliminate the smear layer and reduce post-endodontic pain. A repeat of WL was established again by using EAL as describe before using \#35, \#40, and \# 45 files. The root canals were then desiccated with sterile paper 


\section{Global Journal of Otolaryngology}

cones size \#35 and filled at the same appointment. Gutta-percha cones (Dentsply Maillefer) were laterally condensed with \#20 nickel-titanium spreaders (Dentsply Maillefer) and Sealapex® sealer (Sybron Endo Endodontics, Orange, CA). Entrance openings of anterior teeth were etched and repaired with Fuji IX (GC Corp, Tokyo, Japan). For posterior teeth, a rebuilding was placed with the same method. Finalized the RCT patients received instructions on how to use a $10-\mathrm{cm}$ visual analog scale (VAS) to record post-endodontic pain. After that this score was transferred to a numerical value between 0 and 10 and a verbal scale (none, mild, moderate, intense and unbearable).

\section{Statistical Analysis}

Patients were advised of the probable occurrence of pain for days after RCT and received a survey form to be completed and returned two days after. In it, they proof the occurrence or nonappearance of post-endodontic pain, its period and level of distress rated as follows: mild pain: any discomfort that does not require treatment; moderate pain: pain that demands and is comforted with painkillers; and severe pain: any pain that is not calmed with treatment (analgesics). One hundred and thirtyfour of the 140 surveys were returned correctly responded and, in the date, requested. Of these, 31 belonged to the control group, 35 to TFA group, 35 to WON group and 34 to PTN group. Rests of the 140 were received one day after and were included in the data analysis.

Table 3: Kruskal/Wallis test applied to the post-endodontic pain results for the groups Control group,

\begin{tabular}{|c|c|c|c|}
\hline Instrumentation Technique & n & Mean & Standard Deviation \\
\hline Pain after $24 \mathrm{~h}$ & & & .45 \\
\hline Control Group & 35 & .67 & .63 \\
\hline Twisted File Adaptive & 35 & .5 & .63 \\
\hline Wave OneTM & 35 & .67 & .74 \\
\hline Protaper Next & 35 & & .33 \\
\hline Pain after 48 h & & .18 & .45 \\
\hline Control Group & 35 & .16 & .32 \\
\hline Twisted File Adaptive & 35 & .17 & .45 \\
\hline Wave One & 35 & .16 & \\
\hline Protaper Next & 35 & & \\
\hline
\end{tabular}

Twisted file adaptive, Wave OneTM and Pro Taper Next.

$P$ value $=0.05$

Table 4: Distribution of teeth by Randomization Factors.

\begin{tabular}{|c|c|c|c|c|c|}
\hline 24 Hrs. After & $\begin{array}{c}\text { Control Group (CG) } \\
\text { (n= 35) (\%) }\end{array}$ & $\begin{array}{c}\text { Twisted file } \\
\text { adaptive (TFA) (n= } \\
\text { 35) (\%) }\end{array}$ & $\begin{array}{c}\text { Wave OneTM (WON) } \\
\text { (n= 35) (\%) }\end{array}$ & $\begin{array}{c}\text { Protaper Next (PTN) } \\
\text { (n = 35) (\%) }\end{array}$ & $\begin{array}{c}\text { Total } \\
\text { (n= 140) }\end{array}$ \\
\hline Quantity & & & & $34(97.14)$ & $131(93.57)$ \\
\hline None & $29(82.85)$ & $34(97.14)$ & $34(97.14)$ & $2(5.71)$ & $6(4.28)$ \\
\hline One tablet & $2(5.71)$ & $1(2.85)$ & $1(2.85)$ & 0 & $2(1.42)$ \\
\hline Two tablets & $2(5.71)$ & 0 & 0 & 0 & $1(0.71)$ \\
\hline Three tablets & $1(2.85)$ & 0 & 0 & 0 \\
\hline
\end{tabular}




\section{Group of Teeth}

No statistically significant differences were encountered between groups about occurrence, grade, or length of postendodontic pain among anterior and posterior teeth.

\section{Post-Endodontic Pain Associated with the Arch}

In maxillary teeth, differences among groups were not statistically relevant concerning occurrence, level, or length of post-endodontic pain. In mandibular teeth, post-endodontic pain was significantly lengthier (P .016; Table 3) than maxillary teeth.

\section{Discussion}

Pain is tough to comprehend and measure especially when it occurs unexpectedly in patients. The main inconvenience in learning pain and anxiety is the participant's special assessment and its dimension. For this objective, scheduling the evaluation form has to be entirely understood by patients. In this project, a simple categorization was monitored in the feedback procedure with three classes: minor, modest, and acute. Pre-operative pain is a predictor of post-endodontic pain [20]. Teeth with irreversible pulpitis were allocated for this investigation and were performed RCT in one-visit to avoid any the probable effect of intracanal medication or other issues causing pain and the involucrate teeth in the four groups were released of any early occlusal points after RCT so that improper painful occlusion would not interrupt the results. In this research, the correct measure of WL during RCT was furthermore crucial. WL was calculated with an EAL device and corroborated with an X-ray film. Root ZX locater was employed due its precision has been recognized in two clinical scenarios. [21-24]. As recommended by Herrera et al. [25], electronic WL dimension was cyclic after coronal and middle thirds shaping.

When endodontists associate radiographic analysis and digital root canal measurements, sometimes results do not match. In the time of discrepancy between both sizes, the electronic calculation would be selected, [26-28] as occur in this research. In an early study [29] was demonstrated that the length of the file employed to preserve AF open varied. A size \#10 file was used to conserve working length in this research. Managing major measurements to maintain AP can produce damage to surrounding tissues, hard control in complete RCT. All of these circumstances influence the manifestation of aching. Pushing of endodontic files outside the AF can impulse a variety of toxic products to the neighboring tissues, which can produce pain [30]. Georgepoulou et al. [31] demonstrated a significant incidence of pain if, through the enlarging canal procedure, instruments, or material were involuntarily placed outside the AF instead of keeping them inside the canal. In our research, there is no over instrumentation, working length was maintained in all cases. Nevertheless, AP does not appear to be related to post-endodontic pain in vital condition because of its control during RCT [32].
Moreover, Torabinejad et al. [33] detailed that unintentional over-passage of the instrument, it can happen while calculating $\mathrm{WL}$, does not affect the incidence of post-endodontic pain. Our method was similar to them because likely we employed only thin files to establish the WL. This study supports our results in that apical overextension does not generate post-endodontic pain. Though, it varies from our research in that they did not maintain AP during all the RCT Siqueira et al. [34] discovered the little occurrence of flare-ups subsequent RCT in teeth with necrotic tissue or teeth with the previous RCT if AP was conserved. They identified that maintenance of AP does not affect post-endodontic pain. This condition did not happen in our research because only manage vital teeth. In our study, we reduce the variation in the processes following practices based on suggestions by authors and producers. Clean and shape actions were performed on root segments using brushing, and reciprocating movements individually followed final flushing with cold 6oC 17\% EDTA gently delivered to the WL using a cold (6oC) sterile metallic micro cannula attached to the Endovac supported in an early scientific report [35-37]. Clinical factors studied as sex, age, tooth group, instrumentation, and irrigation type does not affect the success of the treatment only the preoperative pulpal diagnosis and preoperative pain can modify the prognosis of the study.

\section{Conclusion}

The result of this research suggests that the use of intra-canal cryotherapy technique with negative pressure irrigation reduces post-endodontic pain after single-visit RCT. Clinical factors such as sex, age, tooth group, and the instrumentation technique don't affect the results. Previous factors as preoperative pain, and irrigation type, can affect the occurrence of pain.

\section{References}

1. Ince B, Ercan E, Dalli M, Dulgergil CT, Zorba YO, etal. (2009) Incidence of postoperative pain after single- and multi-visit endodontic treatment in teeth with vital and non-vital pulp. Eur J Dent 3(4): 273-279.

2. Watkins CA, Logan HL, Kirchner HL (2002) Anticipated and experienced pain associated with endodontic therapy. J Am Dent Assoc 133(1): 45-54.

3. Torabinejad M, Kettering JD, McGraw JC, Cummings RR, Dwyer TG, et al. (1988) Factors associated with endodontic interappointment emergencies of teeth with necrotic pulps. J Endod14(5): 261-266.

4. Souza RA (2006) The importance of apical patency and cleaning of the apical foramen on root canal preparation. Braz Dent J 17(1): 6-9.

5. Monsef M, Hamedzadeh K, Soluti A (1997) Effect of apical patency on the apical seal of obturated canals. J Endod 23(4): 253.

6. Monsef M, Hamedzadeh K, Soluti A (1998) Effect of apical patency on the apical seal of obturated canals. J Endod 24: 284.

7. Fava L (1998) Acute apical periodontitis: incidence of post-operative pain using two different root canal dressings. Int Endod J 31(5): 343347.

8. Buchanan LS (1989) Management of the curved root canal. J Calif Dent Assoc 17(4): 18-27. 
9. Izu KH, Thomas SJ, Zhang P, Izu AE, Michalek S (2004) Effectiveness of sodium hypochlorite in preventing inoculation of periapical tissues with contaminated patency files. J Endod 30(2): 92-94.

10. Roane JB, Sabala CL, Duncanson MG (1985) The "Balanced Force" Concept for Instrumentation of Curved Canals J Endod 5(11): 203-211.

11. Flanders D (2002) Endodontic patency: how to get it, how to keep it, why it is so important. N J State Dent J 68(3): 30-32.

12. Ferraz CC, Gomes NV, Gomes BP, Zaia AA, Teixeira FB, et al. (2001) Apical extrusion of debris and irrigants using two hands and three engine-driven instrumentation techniques. Int Endod J 34(5): 354 358.

13. Bürklein S, Schëafer E (2012) Apically extruded debris with reciprocating single-file and full-sequence rotary instrumentation systems. J Endod 38(6): 850-852.

14. Yared G (2008) Canal preparation using only one Ni-Ti rotary instrument: preliminary observations. Int Endod J 41(4): 339-344.

15. Gutmann JL, Gao Y (2012) Alteration in the inherent metallic and surface properties of nickel-titanium root canal instruments to enhance performance, durability and safety: a focused review. Int Endod J 45(2): 113-128.

16. Reddy SA, Hicks ML (1998) Apical extrusion of debris using two hands and two rotary instrumentation techniques. J Endod 24(3): 180-183.

17. Al-Omari MAO, Dummer PMH (1995) Canal blockage and debris extrusion with eight preparation techniques. J Endod 21(3): 154-158.

18. Arias A, Azabal M, Hidalgo JJ, de la Macorra JC (2009) Relationship between post endodontic pain, tooth diagnostic factors, and apical patency 35(2): 189-192.

19. Kirchhoff AL, Fariniuk LF, Mello I (2015) Apical extrusion of debris in flat-oval root canals after using different instrumentation systems. J Endod 41(2): 237-241.

20. Vera J, Ochoa Rivera J, Vazquez-Carcaño M, Romero M, Arias A, et al. (2015) Effect of Intracanal Cryotherapy on Reducing Root Surface Temperature. J Endod 41 (11): 1884-1887.

21. Luiz F, Santana D, Correia L (2006) The ability of two apex locators to locate the apical foramen: an in vitro study. J Endod 32(6): 560-562.

22. Tselnik M, Baumgartner J, Gordon Marshall J (2006) An evaluation of Root ZX and Elements diagnostic apex locators. J Endod 31(7): 507509.

23. Welk A, Baumgartner J, Gordon Marshall J (2003) An in vivo comparison of two frequency- based electronic apex locators. J Endod 29(8): 497-500.

24. Dunlap CA, Remeikis NA, BeGole EA, Rauschenberger CR (1998) An in vivo evaluation of an electronic apex locator that uses the ratio method in vital and necrotic canals. J Endod 24(1): 48-50.
25. Herrera MC, Abalos A, Planas J, Llamas R (2007) Influence of apical constriction diameter on Root ZX apex locator precision. J Endod 33(8): 995-998.

26. Lucena Martín C, Robles Gijón V, Ferrer-Luque CM, Navajas Rodriguez de Mondelo JM (2004) In vitro evaluation of the accuracy of three electronic apex locators. J Endod 30(4): 231-233.

27. Kim Park MA, Baughan LW, Hatwell GR (2003) Working length determination in palatal roots of maxillary molars. J Endod 29(1): 5861.

28. Williams CB, Joyce AP, Roberts S (2006) A comparison between in vivo radiographic working length determination and measurement after extraction. J Endod 32(7): 624-627.

29. Caillateau J, Mullaney T (1997) Prevalence of teaching apical patency and various instrumentation and obturation techniques in United States dental schools. J Endod 23(6): 394-396.

30. Nobuhara W, Carnes D, Gilles J (1993) Anti-inflammatory effects of dexamethasone on periapical tissues following endodontic overinstrumentation. J Endod 19(10): 501-507.

31. Georgepoulou M, Anastassiadis P, Sykaras S (1986) Pain after chemo mechanical preparation. Int End J 19(6): 309-314.

32. Fox J, Atkinson J, Dinin A, Greenfield E, Hechtman E, et al. (1970) Incidence of pain following one-visit endodontic treatment. Oral Surg 30(1): 123-130.

33. Torabinejad M, Kettering J, McGraw J, Cummings R, Dwyer T, Tobias $\mathrm{T}$ (1988) Factors associated with endodontic interappointment emergencies of teeth with necrotic pulps. J Endod 14(5): 261-266.

34. Siqueira J, Rôças I, Favieri A, Machado AG, Gahyva SM, et al. (2002) Incidence of postoperative pain after intracanal procedures based on an antimicrobial strategy. J Endod 28(6): 457-460.

35. Modabber A, Rana M, Ghassemi A, Gerressen M, Gellrich NC, et al. (2013) Three-dimensional evaluation of postoperative swelling in treatment of zygomatic bone fractures using two different cooling therapy methods: a randomized, observer-blind, prospective study. Trials 14: 1-10.

36. Bleakley CM, McDonough SM, MacAuley DC, Bjordal J (2006) Cryotherapy for acute ankle sprains: a randomized controlled study of two different icing protocols. Br J Sports Med 40(8): 700-705.

37. Al Nahlawi T, Abo Hatab T, Abd Alrazak M (2016) Effect of intracanal cryotherapy and negative irrigation technique on post endodontic pain. J Contemp Dent Pract 17(2): 990-996. 
(CC) This work is licensed under Creative

(C) BY Col: 10.19080/GJO.2019.20.556046

\section{Your next submission with Juniper Publishers} will reach you the below assets

- Quality Editorial service

- Swift Peer Review

- Reprints availability

- E-prints Service

- Manuscript Podcast for convenient understanding

- Global attainment for your research

- Manuscript accessibility in different formats

( Pdf, E-pub, Full Text, Audio)

- Unceasing customer service

Track the below URL for one-step submission https://juniperpublishers.com/online-submission.php 